\title{
Ability of cyclohexenonic long-chain fatty alcohol to reverse diabetes-induced cystopathy in the rat
}

Motoaki Saito ${ }^{1}$, Yukako Kinoshita ${ }^{1}$, Itaru Satoh ${ }^{1}$, Chiko Shinbori ${ }^{1}$, Hiroto Suzuki $^{2}$, Masashi Yamada ${ }^{2}$, Takeshi Watanabe ${ }^{3}$ and Keisuke Satoh ${ }^{1}$

1: Department of Pathophysiological and Therapeutic Science, Division of Molecular Pharmacology, Tottori University Faculty of Medicine, Yonago, Japan

2: Meiji Dairies Corporation Pharmaceuticals Department, Tokyo, Japan

3: Department of Surgery, Division of Urology, Tottori University Faculty of Medicine, Yonago, Japan

Key Words: urinary bladder, $\mathrm{N}$-hexacosanol, cystopathy, $\mathrm{M}_{2}$ muscarinic receptor, $\mathrm{M}_{3}$ muscarinic receptor, mRNA

2,807 words

Running head: Diabetic rat bladder

\section{Correspondence:}

Motoaki Saito, MD, PhD

Department of Pathophysiological and Therapeutic Science, Division of Molecular Pharmacology, Tottori University Faculty of Medicine, 86 Nishimachi, Yonago, 683-8503, Japan

$$
\begin{array}{ll}
\text { Telephone: } & +81-859-38-6163 \\
\text { FAX: } & +81-859-38-6160
\end{array}
$$

e-mail address: saitomo@grape.med.tottori-u.ac.jp 


\section{Abstract}

Introduction: We investigated the ability of N-hexacosanol, a neurotrophic substance, to reverse diabetes-induced cystopathy in the rat.

Materials and methods: Eight-week-old male SD rats were divided randomly into four age-matched groups. In three of these groups, diabetes was induced by streptozotocin (50 mg/kg i.p.). Four weeks after the induction of diabetes, the three groups received another four weeks of treatment by vehicle or N-hexacosanol (2, or $8 \mathrm{mg} / \mathrm{kg}$, i.p. every day). The serum glucose and serum insulin levels were determined, and the bladder functions were estimated by voiding behavior studies, cystometric studies, and functional studies using carbachol and $\mathrm{KCl}$. The participation levels of $\mathrm{M}_{2}$ and $\mathbf{M}_{3}$ receptors were investigated by real-time PCR and immunohistochemical staining. Typical H\&E staining was also performed.

Results: Treatment with N-hexacosanol did not alter the rats' diabetic status, but did significantly improve the diabetes-induced dysfunction of the detrusor in a dose-dependent manner. Furthermore, N-hexacosanol significantly reversed the up-regulation of muscarinic $\mathrm{m}_{2}$ and $\mathrm{m}_{3}$ receptor mRNAs in STZ-diabetic rats. Muscarinic $\mathrm{M}_{2}$ and $\mathrm{M}_{3}$ receptors were localized in detrusor and urothelium, and there was no difference between any of the groups in the distribution of muscarinic $\mathrm{M}_{2}$ and $\mathrm{M}_{3}$ receptors.

Conclusion: These results indicate that N-hexacosanol has a beneficial effect on hyperreactivity in the diabetic detrusor by ameliorating over-expression of muscarinic $\mathrm{m}_{2}$ and $\mathrm{m}_{3}$ receptor mRNAs. 


\section{Introduction}

It has been reported that 26-78\% of patients with diabetes mellitus have disease-induced dysfunction of the lower urinary tract, and diabetic cystopathy is a common complication of diabetes mellitus [1- 3]. These urinary tract dysfunctions are induced primarily by diabetes-associated neuropathy [1- 3]. Several rodent models have been used to investigate type I diabetes [4]. Streptozotocin (STZ), which causes sub-total pancreatic islet necrosis, has been widely used to induce insulin-dependent diabetic states in experimental animals. Residual insulin production enables these rats to survive without insulin supplementation for extended periods of time. Thus, STZ-induced diabetic rats are widely used to investigate type I diabetes [4]. These rats show hyperglycemia, hypoinsulinemia, and inhibited weight gain during feeding. Furthermore, significant increases in bladder weight and residual urine volume, hypercontractility to carbachol, and up-regulation of muscarinic receptors in the bladder dome have been reported in this diabetic model [4-8].

The tropical plant Hygrophilia erecta Hochr. has been shown to contain some cyclohexenonic long-chain fatty alcohols (N-hexacosanols). N-hexacosanols have neurotrophic effects on cultured neurons from the cerebral cortex. [9, 10]. As 
$\mathrm{N}$-hexacosanol has a neurotrophic effect, we have reported that N-hexacosanol exerts beneficial effects on peripheral neuropathy and cystopathy in streptozotocin-induced diabetic rats, and that $\mathrm{N}$-hexacosanol treatment can normalize diabetes-induced alterations of motor sciatic nerve conduction [7, 8, 11]. However, the detailed mechanisms underlying the action of diabetes-induced cystopathy by this drug remain unclear. In this study, we tried to investigate N-hexacosanol's ability to reverse diabetes-induced cystopathy and the possible mechanism underlying this ability in STZ-induced diabetic rats. 


\section{Materials and Methods}

\section{Animal model}

All animal experiments were performed in accordance with the guidelines established by the Tottori University Committee for Animal Experimentation. Diabetes was induced in 8-week-old male Sprague-Dawley rats (SLC, Shizuoka, Japan) by administering an intraperitoneal injection of streptozotocin (STZ) (50 mg/kg) dissolved in $0.1 \mathrm{M}$ citrate-phosphate buffer $(\mathrm{pH} 4.2)$ [8, 11, 12]. The rats were divided randomly into four age-matched groups $(n=6-8)$. One group was a non-diabetic control (group A), and was administered $0.1 \mathrm{M}$ citrate-phosphate buffer ( $\mathrm{pH}$ 4.2) without N-hexacosanol; diabetes was induced in the three others. Four weeks after the induction of diabetes, animals were treated for another four weeks with a vehicle (groups A and B) or with N-hexacosanol at a daily dose of 2 or $8 \mathrm{mg} / \mathrm{kg}$ for another four weeks (groups C and D, respectively). Two days after the injection of STZ or the vehicle, the induction of diabetes was confirmed by measuring urinary glucose with Pretest 3a II (Wako Pure Chemical, Osaka, Japan). In our preliminary study demonstrated that $\mathrm{N}$-hexacosanol did not effect on non diabetic rat bladder function (data not shown). In every rat, N-hexacosanol (groups C and D) or vehicle (groups A and B) were injected i.p. every day beginning four weeks after the induction of diabetes $[8,11,12]$. All of the groups were kept under identical conditions and had access to food and drinking water ad libitum. Eight weeks after the induction of diabetes, the rats were subjected to cystometric examination and then sacrificed with an overdose of pentobarbital (60 mg, i.p.). Blood samples were collected from the vena cava, and the 
bladder dome was removed and placed in Krebs-Henseleit solution. The blood samples and bladder domes were then used for functional, biochemical, and histological studies.

\section{Serum glucose and insulin measurement}

Serum glucose concentrations in the experimental rats were measured by the hexokinase method (Glucose C II , Wako Pure Chemical, Osaka, Japan), which was carried out according to the kit manufacturer's instructions. Insulin concentrations were also measured by ELISA according to the manufacturer's instructions (Rat Insulin ELISA, Mercodia AB, Uppsala, Sweden).

\section{Voiding behavior studies}

Voiding behavior studies were performed according to methods used in our previous study [8]. All rats received water ad libitum from the time they were initially placed in the cage. The parameters of the micturition reflex obtained were micturition frequency and total urine output.

\section{Cystometric studies}

The cystometric studies were performed according to methods used in our previous report [8]. The following parameters were evaluated according to our previous reports: bladder capacity, maximum detrusor pressure during voiding, single-voided volume, and residual urine volume. 


\section{Tissue preparation and measurement of contractile force in the bladder}

Functional studies were conducted according to methods used in our previous reports [8]. Razor blades were used to cut uniform longitudinal strips of the posterior wall of the bladder dome $(1.5 \times 5 \mathrm{~mm})$. These muscle strips were mounted in organ baths (25 $\mathrm{ml}$ ) containing Krebs-Henseleit solution and were bubbled with $5 \% \mathrm{CO}_{2}$ and $95 \% \mathrm{O}_{2}$ $\left(37^{\circ} \mathrm{C}\right.$ ). $\quad$ One hook was suspended from a transducer (type 45196A, San-ei Instruments, Tokyo, Japan), and the lower hook was fixed to a plastic support leg attached to a micrometer (Mitutoyo, Tokyo, Japan). Changes in the tone of the strips were measured isometrically by means of force transducers, and the data were recorded on a personal computer (Macintosh G3, Apple Computer) with the use of software Chart v 3.6.9 and a PowerLab/16sp data acquisition system (AD Instruments). Cumulative concentration-response curves to carbachol and $\mathrm{KCl}(100 \mathrm{mM})$ were constructed.

\section{Real-time PCR (quantification of muscarinic $\mathrm{m}_{2}$ and $\mathrm{m}_{3}$ receptor mRNAs)}

Muscarinic $\mathrm{m}_{2}$ and $\mathrm{m}_{3}$ receptor mRNAs in the experimental bladder dome were measured by real-time PCR methods. The RNA was purified by RNeasy Mini Kit (Qiagen, Valencia, CA) according to the manufacturer's instructions. A reverse transcriptase $(\mathrm{RT})$ mixture $(28 \mu \mathrm{l})$ containing $2 \mu \mathrm{g}$ of total RNA was made and incubated at $37{ }^{\circ} \mathrm{C}$ for 60 min according to a previously reported method [13]. Five microliters of the mixture was used for real-time PCR, which was carried out using a 
LightCycler thermal cycler system with a LightCycler-FastStart DNA Master Hybridization Probe according to the manufacturer's instructions (Roche Diagnostics, Tokyo, Japan) [14]. The primers and probe sequences specific to the genes of $\mathbf{M}_{2}$ and $\mathbf{M}_{3}$ receptors are shown in Table 1. The predicted product sizes of $\mathbf{M}_{2}$ and $\mathbf{M}_{3}$ receptors were $148 \mathrm{bp}$ and $149 \mathrm{bp}$, respectively. The primer and probe of the $\beta$-actin used were from the LightCycler-Primer/Probe Set (rat). A total of $15 \mu$ l of solution was used for the sample. The specificity of the reaction was confirmed by melting curve analysis and $2 \%$ agarose gel electrophoresis. The $\beta$-actin gene was used as the internal standard and analyzed by real-time PCR using the same RT mixture.

\section{Histological examination of the rat bladder dome}

After fixation, the tissues were embedded in paraffin. Five micron-thick tissue sections were cut from these paraffin blocks. All of the bladder specimens were stained using hematoxylin and eosin $(\mathrm{H} \& \mathrm{E})$ staining. The stained tissue sections of the experimental bladder dome were viewed at a magnification of X 40-400 under a light microscope (BX50, Olympus, Tokyo, Japan) using a digital camera (HC-3000, Fujix, Tokyo, Japan). The serial sections were also subjected to immunohistochemical stains for muscarinic $\mathrm{M}_{2}$ and $\mathrm{M}_{3}$ receptors. Briefly, after sections were deparaffinized, they were then reacted overnight with rabbit anti-muscarinic $\mathrm{M}_{2}$ receptor or muscarinic $\mathrm{M}_{3}$ receptor polyclonal antibody (Acris Antibodies GmbH, Hiddenhausen, Germany) at 1:1000 and 1:500 dilutions, respectively. The specifically bounds of first bound antibodies were visualized by Histofine simple stain rat MAX-PO with a Histofine 
simple stain substrate (Nichirei Co., Tokyo, Japan). Mayer's hematoxylin was used for counterstaining. Negative controls were established for each group according to the procedure mentioned above, but without the Histofine simple stain rat MAX-PO. The stained tissue sections were viewed at a magnification of X 40-400 under a light microscope (BX50, Olympus) using a digital camera (HC-3000, Fujix).

\section{Data analysis}

The $\mathrm{ED}_{50}$ and $\mathrm{E}_{\max }$ values were obtained by a Macintosh computer (G3) loaded with Chart v3.6.9 software and a PowerLab/16sp data acquisition system. Contractile data were calculated as grams of active force per cross sectional area in square millimeters. The cross-sectional area was calculated using the following equation: cross-sectional area $=$ weight $/$ (length $\times 1.05$ ), where 1.05 is the assumed density of the muscle [8]. The expression of muscarinic $\mathrm{m}_{2}$ and $\mathrm{m}_{3}$ receptor mRNAs was quantified according to the expression of $\beta$-actin mRNAs in the experimental rat bladder domes. A statistical comparison of differences between groups was performed using analysis of variance and Fisher's multiple comparison tests. $\mathrm{P}<0.05$ was regarded as the level of significance.

\section{Drugs and chemicals}

3-(15 Hydroxypentadecyl)-2,4,4-trimethyl-2-cyclohexen 1-one (N-hexacosanol) was obtained from Meiji Milk Products Co., Ltd., Tokyo, Japan. Carbachol was purchased from Sigma (St. Louis, MO). Streptozotocin (STZ) was purchased from Wako Pure 
Chemical (Osaka, Japan). All other chemicals were available commercially and of reagent grade. 


\section{Results}

\section{General features of the experimental animals}

The data obtained regarding the general features and serum concentrations of insulin and glucose in the experimental animals are shown in Table 2. The diabetic rats treated without $\mathrm{N}$-hexacosanol showed no weight gain and a significant increase in bladder weight during the experimental period. The diabetic rats displayed significantly higher serum glucose and lower serum insulin levels than those of the control rats. Treatment with $\mathrm{N}$-hexacosanol (at either 2 or $8 \mathrm{mg} / \mathrm{kg}$ ) neither increased body weight nor reduced serum glucose and insulin levels of the diabetic animals. These data agree with our previous reports. Diabetic rats treated without $\mathrm{N}$-hexacosanol showed a significant increase in bladder weight during the initial four weeks, and treatment with $\mathrm{N}$-hexacosanol failed to inhibit an additional increase of bladder weight.

\section{Voiding behavior studies}

The voiding behavior data and the cystometric results for the experimental animals are shown in Table 3. In the voiding behavior studies, urine production, micturition frequency, and single voided volume in the diabetic rats (Group B) were significantly larger than that in the control rats (Group A). Additional treatment with $\mathrm{N}$-hexacosanol (at both 2 and $8 \mathrm{mg} / \mathrm{kg}$ ) had no effect on urine production, single voided volume, or micturition frequency. 


\section{Cystometric studies}

In the cystometric studies, the maximum detrusor pressure (Pdet) in the diabetic rats (group B) was significantly higher than that in the controls. The single voided volume in the diabetic rats treated with or without $\mathrm{N}$-hexacosanol was markedly higher than that of the controls. The residual urine volume in the diabetic rats (group B) was markedly greater than that of the controls. Although the single voided volume was not altered by treatment with $\mathrm{N}$-hexacosanol, these two parameters, i.e., maximum detrusor pressure (Pdet) and residual urine, were significantly improved by treatment with the high dose of N-hexacosanol.

\section{Measurement of contractile response to carbachol and $100 \mathrm{mM} \mathrm{KCl}$}

The $E_{\max }$ values for the contractile response of the longitudinal muscles to carbachol and $\mathrm{KCl}(100 \mathrm{mM})$ were determined (Table 4). Diabetes-induced detrusor hyperreactivity by carbachol was ameliorated by N-hexacosanol in a dose-dependent manner. The low-dose (2 mg/kg) treatment with $\mathrm{N}$-hexacosanol tended to improve the hyperreactivity of the rat detrusor. The high-dose $(8 \mathrm{mg} / \mathrm{kg})$ treatment with N-hexacosanol significantly ameliorated diabetes-induced hyperreactivity of the detrusor in the diabetic group. However, the contractile responses to $100 \mathrm{mM} \mathrm{KCl}$ and the $\mathrm{ED}_{50}$ values with respect to carbachol were not altered by either the induction of diabetes or the N-hexacosanol treatment (Table 4).

Measurement of muscarinic $\mathrm{m}_{2}$ and $\mathrm{m}_{3}$ receptor mRNAs in the rat bladder dome 
Table 5 shows the expression of $m_{2}$ and $m_{3}$ muscarinic receptor mRNAs in the bladder dome. The expression of both mRNAs was significantly higher in the diabetic group (B) than in the control group (A). N-hexacosanol ameliorated the expression of these mRNAs in a dose-dependent manner. Furthermore, in the control group (group A), the expression level of the $\mathrm{m}_{3}$ receptor mRNAs was about 25-fold compared to that of the $\mathrm{m}_{2}$ receptor mRNAs; in all other groups, the expression level of the $\mathrm{m}_{3}$ receptor mRNAs was higher than that of the $\mathrm{m}_{2}$ receptor (10- to 25-fold).

\section{Histological examination of rat bladder dome}

Typical H\&E staining results obtained from the histological examination are shown in Figs. 1 and 2. Typical H\&E and immunohistochemical staining results obtained from histological examination are shown in Figs. 1 and 2. In both muscarinic $\mathbf{M}_{2}$ and $\mathbf{M}_{3}$ receptors immunohistochemical stainings, immunohistological positive was observed in the bladder smooth muscle and urothelium in the rat (Fig. 1 and 2). In the smooth muscle layer, immunohistological positive were seen inside and between the muscle bundles. 


\section{Discussion}

Latifpour et al. [5] reported increased numbers of muscarinic receptors associated with the contractile responses to muscarinic agonists in the bladder dome in STZ diabetic rats. Our observations in this study support their report. We demonstrated the ameliorative effects of $\mathrm{N}$-hexacosanol on diabetes-induced hyperreactivity in the rat detrusor. This may explain why N-hexacosanol rescues damaged peripheral neurons [7]. The precise mechanism underlying this effect was unclear, and we suspected that $\mathrm{N}$-hexacosanol worked on the muscarinic receptor system. The increase in maximal contractions without changes in the $\mathrm{ED}_{50}$ values due to the potent cholinergic agonist carbachol in 8-week STZ-induced diabetic rat detrusor indicates that the number of muscarinic receptors increases without any change in receptor affinity in the diabetic condition. Therefore, it is possible that N-hexacosanol could ameliorate detrusor hyperreactivity by regulating the expression level of the muscarinic receptors. In order to investigate the possible mechanism underlying this effect, we measured the expression levels of muscarinic $\mathrm{m}_{2}$ and $\mathrm{m}_{3}$ receptor mRNAs by real-time PCR. It is well known that both $\mathrm{M}_{2}$ and $\mathrm{M}_{3}$ muscarinic receptors are expressed in the detrusor and influence contraction through distinct pathways. Despite numerous reports concerning the effects of diabetes mellitus on the lower urinary tract, little is known about the influence of diabetes on cholinergic receptors at the mRNA level. In a previous study using a binding assay, muscarinic receptor levels were reported to be up-regulated in

diabetic rat bladder domes $[5,6]$. The present study demonstrates that the expression of 
$\mathrm{m}_{2}$ and $\mathrm{m}_{3}$ receptor mRNAs was higher in diabetic rats compared to the controls, and that N-hexacosanol ameliorated these increases in the rat detrusor. The present data indicate the possibility that the over-expression of muscarinic $\mathrm{m}_{2}$ and $\mathrm{m}_{3}$ receptor mRNAs is related to the hypercontraction of the detrusor in diabetic rats. Furthermore, N-hexacosanol partially normalized this hypercontraction by reducing the expression levels of the muscarinic $m_{2}$ and $m_{3}$ receptor mRNAs. Recently, Mansfield et al. reported that although $75 \%$ and $25 \%$ of expressed muscarinic receptors were $\mathrm{M}_{2}$ and $M_{3} / M_{5}$ receptors, respectively, the expression of $m_{3}$ receptor mRNAs was significantly higher than that of $\mathrm{m}_{2}$ receptor mRNAs in the human detrusor and epithelium as measured by quantitative competitive RT-PCR methods [15]. Although the stability of muscarinic $\mathrm{m}_{2}$ receptor mRNAs is unclear, this instability may be attributable to variation in mRNA translation rates, which are governed by a variety of hormonal and cellular events, and/or to mRNA stability [15]. Fraser and Lee reported that muscarinic $\mathrm{m}_{3}$ receptor mRNA expression was extremely stable compared to that of muscarinic $\mathrm{m}_{1}$ receptor [16].

The immunohistochemical staining results obtained from the histological studies indicated that muscarinic $\mathrm{M}_{2}$ and $\mathrm{M}_{3}$ receptors were expressed in both the smooth muscle and urothelium in the control. The $\mathrm{M}_{2}$ receptor antibody was raised in rabbits to a synthetic peptide covalently attached to a carrier protein. Antibodies to the carrier protein could have stained similar epitopes in the tissue which are not specific for the receptor subtype. This is particularly true if the carrier protein is the commonly used fusion protein glutathione-S-transferase. Leaving out the secondary antibody, 
enzyme conjugate (Histofine MAX-PO) will always produce a negative section even if $100 \%$ of the binding is non-specific and therefore this does not prove that the primary antibody is specifically bound specifically to the muscarinic receptor subtype in the tissue. So, in this study, we can not rule out that immunohistological positive findings were only specific for the receptor subtype. There was no difference in distribution between any of the groups in this study. Some reports indicated the existence of muscarinic $\mathrm{M}_{2}$ and $\mathrm{M}_{3}$ receptors in the urothelium $[17,18]$. Although the precise role of these receptors in the urothelium is unclear, Yoshida and his associates have reported that the presence of acetyltransferase immunoreactivity in both the smooth muscle layer and in the urothelium suggests that a non-neural cholinergic system is activated in the urothelium of the bladder [18].

Recently, Torimoto and associates, as well as the present authors, have reported that diabetes induces an increase in maximum detrusor pressure during voiding; this increase occurred by urethral dysfunction associated with diabetic neuropathy [8, 19]. From our previous and present data, it is possible that N-hexacosanol has the ability not only to prevent but also to reverse effects of diabetes-induced urethral dysfunction. As N-hexacosanol's reversal effects take place according to a mechanism that differs from that of insulin [20], it is possible that insulin treatment, if administered concomitantly with N-hexacosanol treatment, may prevent or reverse diabetic peripheral neuropathy. However, the detailed mechanism of this preventive effect remains 
unclear, and warrants further study.

\section{Acknowledgments}

We thank Prof. E. Nanba and Ms. K. Adachi for their assistance. This study was supported by a grant from the Ministry of Education, Science, and Culture of Japan (\#14704041) and by a research grant from the President of Tottori University (2005). 


\section{Reference}

[1] Faerman I, Maler M, Jadzinsky M, et al. Asymptomatic neurogenic bladder in juvenile diabetics. Diabetologia 1971; 7: 168-172.

[2] Bradley WE. Diagnosis of urinary bladder dysfunction in diabetes mellitus. Ann Intern Med 1980; 92: 323- 326.

[3] Kaplan SA, Te AE, Blaivas JG. Urodynamic findings in patients with diabetic cystopathy. J Urol 1995; 153: 342-344.

[4] Sima AA, Sugimoto K. Experimental diabetic neuropathy: an update. Diabetologia 1999; 42: 773-788.

[5] Latifpour J, Gousse A, Kondo S, et al. 1989. Effects of experimental diabetes on biochemical and functional characteristics of bladder muscarinic receptors. J Pharmacol Exp Ther 1989; 248: 81-89.

[6] Fukomoto Y, Yoshida M, Weiss RM, Latifpour J. Reversibility of diabetes- and diuresis-induced alterations in rat bladder dome muscarinic receptors. Diabetes 1994; 43: 819-826. 
[7] Watanabe T, Miyagawa I. Effect of long-chain fatty alcohol on peripheral nerve conduction and bladder function in diabetic rats. Life Sci 2002; 70: 2215-2224.

[8] Suzuki H, Saito M, Kinoshita Y, et al. 2006. Preventive effect of cyclohexenonic long-chain fatty alcohol on diabetic neuropathy in the rat bladder. Can J Physiol Pharmacol 2006; 84: 195-201..

[9] Borg J, Toazara J, Heitter H, et al. Neurotrophic effect of naturally occurring long-chain fatty alcohols on cultured CNS neurons. FEBS lett, 1987; 213: 406-410.

[10] Luu B, de Aguilar JLG, Junges CG. Cyclohexenonic long-chain fatty alcohols as neuronal growth stimulators. Molecules 2000; 5: 1439-1460.

[11] Satoh I, Saito M, Kinoshita Y, et al. Effects of cyclohexenonic long-chain fatty alcohol on diabetic rat trachea. Life Sci 2005; 77: 2030-2039.

[12] Kinoshita Y, Saito M, Satoh I, et al. General administration of cyclohexenonic long-chain fatty alcohol ameliorates hyperreactivity of STZ-induced diabetic rat aorta. Life Sci 2006, 78: 1508-1514.

[13] Saito M, Tominaga L, Nanba E, Miyagawa I. Expression of Heat Shock Protein 70 and its mRNAs during ischemia-reperfusion in the rat prostate. Eur J Pharmacol 2004; 
487: 199-203.

[14] Wittwer CT, Ririe KM, Andrew RV, et al. The LightCycler: a microvolume multisample fluorometer with rapid temperature control. Biotechniques 1997; 22:176-181.

[15] Mansfield KJ, Liu L, Mitchelson FJ, et al. Muscarinic receptor subtypes in human bladder detrusor and mucosa, studied by radioligand binding and quantitative competitive RT-PCR: changes in ageing. Br J Pharmacol 2005; 144:1089-1099.

[16] Fraser CM, Lee NH. Regulation of muscarinic receptor expression by changes in mRNA stability. Life Sci 1995; 56: 899-906.

[17] Andersson KE, Yoshida M. Antimuscarinics and the overactive detrusor--which is the main mechanism of action? Eur Urol, 2003; 43:1-5.

[18] Yoshida M, Miyamae K, Iwashita H, et al. Management of detrusor dysfunction in the elderly: changes in acetylcholine and adenosine triphosphate release during aging.Urology 2004; 63:17-23.

[19] Torimoto K, Hirao Y, Matsuyoshi H, et al. Alpha-1 Adrenergic mechanism in diabetic urethral dysfunction in rats. J Urol 2005; 173: 1027-1032. 
[20] Damge C, Hillaere-Buys D, Koeng M, et al. Effect of N-hexacosanol on insulin secretion in the rat. Eur J Pharmacol 1995; 274: 133-139. 


\section{Figure legends}

Figure 1. H\&E and immunohistochemical stainings in the control rat bladder dome.

The muscarinic $\mathrm{M}_{2}$ and $\mathrm{M}_{3}$ receptors were expressed in the bladder smooth muscle and urothelium in the control rats. (x400).

Figure 2. H\&E and immunohistochemical stainings in the diabetic rat bladder dome.

The muscarinic $\mathrm{M}_{2}$ and $\mathrm{M}_{3}$ receptors were expressed in the bladder smooth muscle and urothelium in the diabetic rats. (x400). 
Table 1. Oligonucleotide primers and probes used for amplification of $\mathbf{M}_{2}$ and $\mathbf{M}_{3}$ muscarinic receptors

\begin{tabular}{|c|c|c|}
\hline Gene & Position & Oligonucleotide sequence 5'-3' \\
\hline $\mathrm{M}_{2}$ & (primer) forward $(1390-1409)$ & 5’-CCACTCCAGAGATGACAACT-3’ \\
\hline $\mathrm{M}_{2}$ & (primer) reverse $(1519$ - 1537) & 5’-GGCTACAACGTTC- TGCTTT-3’ \\
\hline $\mathrm{M}_{3}$ & (primer) forward $(1227-1245)$ & 5’-GGACTGTGGATGT- GGAGAG-3' \\
\hline $\mathrm{M}_{3}$ & (primer) reverse $(1358-1375)$ & 5’-CGAGGAGTTGGTGTCAGA \\
\hline $\mathrm{M}_{2}$ & (probe) forward $(1433-1460)$ & 5’-CCAACTAGTTCTACAGTGGTACTCGTTGGGGTGT-3’ \\
\hline $\mathrm{M}_{2}$ & (probe) reverse $(1462-1494)$ & 5’-XАСАCATCACCTTTTTG- GGCCTTGGTGACT-3’ \\
\hline $\mathrm{M}_{3}$ & (probe) forward (1267 - 1284) & 5’-CCA- GAAGAGCATGGGTGATGGTGACAACT-3’ \\
\hline $\mathrm{M}_{3}$ & (probe) reverse $(1286-1325)$ & 5’XGT- CAGAAGGATTTCACCAAGCTTCCCATCCT-3’ \\
\hline
\end{tabular}


Table 2. General features of the experimental rats

\begin{tabular}{|c|c|c|c|c|c|c|}
\hline & \multicolumn{3}{|c|}{ Body Weight (g) } & \multirow[b]{2}{*}{ Bladder weight (g) } & \multirow[b]{2}{*}{ Serum glucose (mg/dl) } & \multirow[b]{2}{*}{ Serum insulin $(\mu \mathrm{g} / \mathrm{l})$} \\
\hline & 8 weeks old & 12 weeks old & 16 weeks old & & & \\
\hline A & $242.9 \pm 3.0$ & $423.6 \pm 5.9$ & $498.8 \pm 10.1$ & $0.131 \pm 0.06$ & $172.8 \pm 13.9$ & $2.39 \pm 0.660$ \\
\hline B & $246.8 \pm 6.4$ & $259.5 \pm 17.2 *$ & $231.8 \pm 23.5 *$ & $0.264 \pm 0.03 *$ & $405.0 \pm 54.3 *$ & $0.17 \pm 0.009 *$ \\
\hline $\mathrm{C}$ & $250.4 \pm 4.7$ & $251.0 \pm 17.0 *$ & $229.0 \pm 25.4 *$ & $0.232 \pm 0.022 *$ & $314.4 \pm 46.9 *$ & $0.17 \pm 0.010 *$ \\
\hline $\mathrm{D}$ & $253.3 \pm 5.1$ & $257.0 \pm 16.1 *$ & $237.0 \pm 17.1 *$ & $0.241 \pm 0.019 *$ & $364.8 \pm 34.3 *$ & $0.16 \pm 0.004 *$ \\
\hline
\end{tabular}

A: control rats, B: diabetic rats treated with sham, C: diabetic rats treated with $\mathrm{N}$-hexacosanol (2 mg/kg), and D: diabetic rats treated with N-hexacosanol (8 $\mathrm{mg} / \mathrm{kg})$. Data are shown as mean \pm SEM of six to eight separated determinations in each group. *) significantly different from A group. 
Table 3. Voiding behavior studies and cystometrogram data in the experimental rats

\begin{tabular}{|c|c|c|c|c|c|}
\hline & micturion frequency (/day) & urine production (ml/day) & Pdet $\left(\mathrm{cmH}_{2} \mathrm{O}\right)$ & single voided volume (ml) & residual urine $(\mathrm{ml})$ \\
\hline A & $10.8 \pm 1.9$ & $10.7 \pm 0.7$ & $39.1 \pm 3.3$ & $0.39 \pm 0.05$ & $0.046 \pm 0.007$ \\
\hline B & $43.9 \pm 4.8 *$ & $115.3 \pm 13.1 *$ & $52.4 \pm 4.6 *$ & $0.69 \pm 0.11 *$ & $0.573 \pm 0.038 \dagger$ \\
\hline $\mathrm{C}$ & $49.0 \pm 6.3 *$ & $99.9 \pm 14.2 *$ & $52.1 \pm 4.2 *$ & $0.68 \pm 0.11 *$ & $0.220 \pm 0.016 \ddagger$ \\
\hline $\mathrm{D}$ & $38.8 \pm 6.4 *$ & $97.5 \pm 18.9 *$ & $41.6 \pm 2.1 * *$ & $0.69 \pm 0.11 *$ & $0.207 \pm 0.015 \ddagger$ \\
\hline
\end{tabular}

A: control rats, B: diabetic rats treated with sham, C: diabetic rats treated with N-hexacosanol (2 mg/kg), and D: diabetic rats treated with $\mathrm{N}$-hexacosanol $(8 \mathrm{mg} / \mathrm{kg})$. Data are shown as mean $\pm \mathrm{SEM}$ of six to eight separated determinations in each group. *) significantly different from A group. ${ }^{* *}$ ) significantly different from B and C groups. $\dagger$ ) significantly different from the other groups. ‡) significantly different from A and B groups. 
Table 4. Functional studies in the experimental rats

\begin{tabular}{lccc}
\hline & $\operatorname{Emax}\left(\mathrm{g} / \mathrm{mm}^{2}\right)$ & $\mathrm{ED}_{50}\left(10^{-7} \mathrm{M}\right)$ & $\mathrm{KCl}\left(\mathrm{g} / \mathrm{mm}^{2}\right)$ \\
\hline $\mathrm{A}$ & $2.35 \pm 0.16$ & $15.7 \pm 2.6$ & $1.69 \pm 0.14$ \\
$\mathrm{~B}$ & $3.29 \pm 0.33^{*}$ & $14.0 \pm 2.1$ & $1.70 \pm 0.17$ \\
$\mathrm{C}$ & $2.81 \pm 0.26$ & $17.7 \pm 2.3$ & $1.70 \pm 0.16$ \\
$\mathrm{D}$ & $2.42 \pm 0.18 \dagger$ & $21.0 \pm 2.4$ & $1.59 \pm 0.10$ \\
\hline
\end{tabular}

A: control rats, B: diabetic rats treated with sham, C: diabetic rats treated with $\mathrm{N}$-hexacosanol (2 mg/kg), and D: diabetic rats treated with $\mathrm{N}$-hexacosanol $(8 \mathrm{mg} / \mathrm{kg})$. Data are shown as mean $\pm \mathrm{SEM}$ of six to eight separated determinations in each group. Emax and ED50 values are for carbachol. $\mathrm{KCl}$ means contractile force to $100 \mathrm{mM} \mathrm{KCl.}{ }^{*}$ ) significantly different from A and D groups. $\quad$ †) significantly different from B and C groups. 
Table 5. Expression of muscarinic $\mathbf{M}_{2}$ and $\mathbf{M}_{3}$ receptor mRNAs in the bladder dome

\begin{tabular}{lcc}
\hline & $\mathbf{M}_{2} / \beta$-actin $\left(\times 10^{-4}\right)$ & $\mathbf{M}_{3} / \beta$-actin $\left(\times 10^{-4}\right)$ \\
\hline A & $1.99 \pm 0.56$ & $46.9 \pm 6.2$ \\
B & $10.02 \pm 3.52^{*}$ & $101.3 \pm 18.8 \dagger$ \\
C & $4.87 \pm 1.16^{* *}$ & $82.9 \pm 14.9 \ddagger$ \\
D & $3.86 \pm 0.93^{*}$ & $61.9 \pm 7.5$ \\
\hline
\end{tabular}

Expression of muscarinic $\mathrm{M}_{2}$ and $\mathrm{M}_{3}$ receptor mRNAs were normalized with that of $\square$-actin mRNAs. A: control rats, B: diabetic rats treated with sham, C: diabetic rats treated with $\mathrm{N}$-hexacosanol (2 mg/kg), and D: diabetic rats treated with $\mathrm{N}$-hexacosanol (8 mg/kg). Data are shown as mean \pm SEM of six to eight separated determinations in each group. ${ }^{*}$ ) significantly different from the other groups. **) significantly different from A and B groups. †) significantly different from A and D groups. ‡) significantly different from A group. 

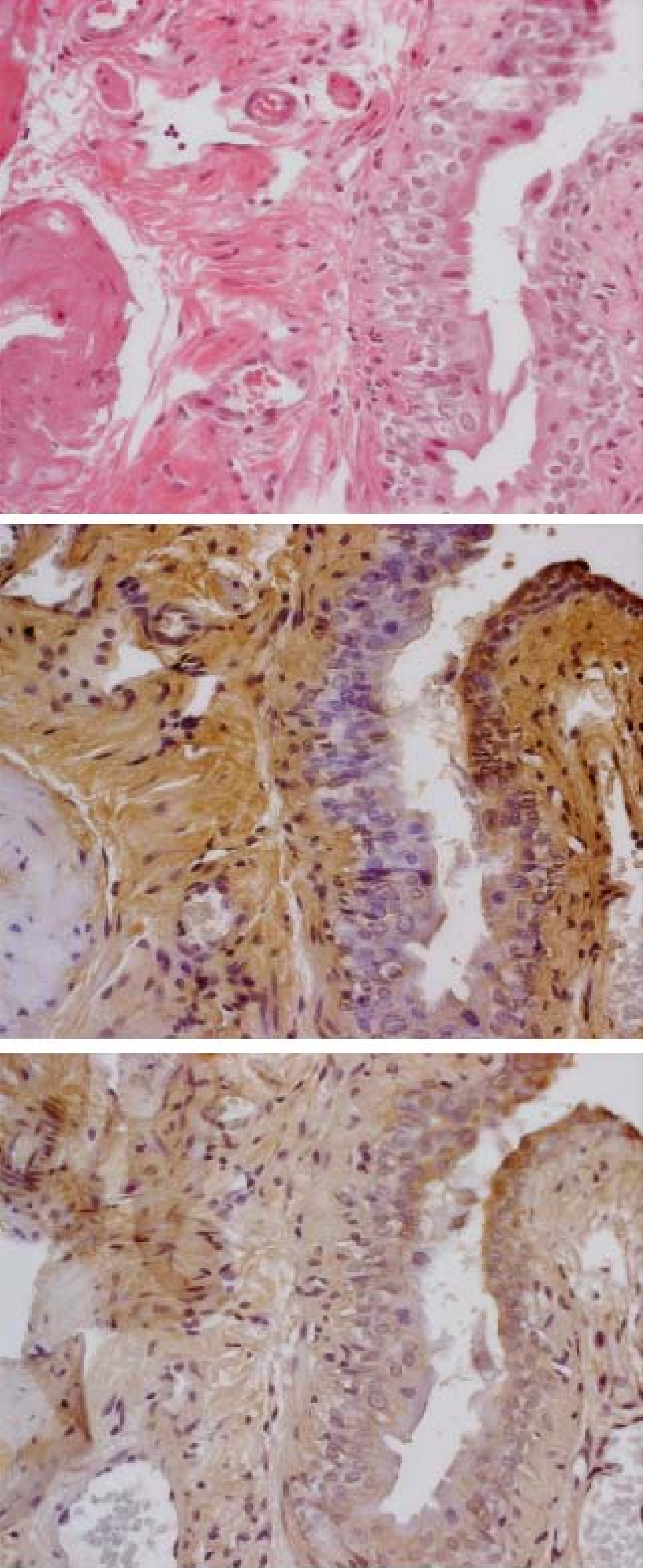

H\&E Staining

Muscarinic $\mathrm{M}_{2}$ receptor

Muscarinic $\mathrm{M}_{3}$ receptor 